\title{
AGENTE COMUNITÁRIO DE SAÚDE: PERCEPÇÕES NAESTRATÉGIA SAÚDE DA FAMÍLIA
}

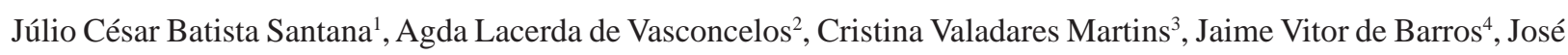
Mateus Soares ${ }^{5}$, Bianca Santana Dutra ${ }^{6}$

RESUMO: O estudo teve como objetivo compreender o significado de ser um Agente Comunitário de Saúde-ACS em um Programa Saúde da Família. Pesquisa descritiva, qualitativa, com inspiração fenomenológica que buscou a essência do discurso do ACS do município de Sete Lagoas-MG. As entrevistas foram gravadas com sete ACS a partir da questão norteadora: Qual a sua percepção como Agente Comunitário de Saúde na Estratégia Saúde da Família? A análise compreensiva das falas possibilitou a construção de cinco categorias: ACS, elo entre a equipe multiprofissional e a comunidade; valorização profissional; papel do ACS na equipe multiprofissional e sua contribuição para a mudança do modelo de atenção básica; formação profissional; condições de trabalho insalubres. Evidenciou-se que os Agentes de Saúde da Família têm conhecimento e consciência do seu papel dentro da equipe multiprofissional, sentem-se despreparados para exercer todas as suas atribuições, desvalorizados em relação à comunidade e a outros membros da equipe. Percebem os riscos ocupacionais da profissão e a falta de ações para minimização destes, além da baixa remuneração.

PALAVRAS-CHAVE: Programa saúde da família; Cuidados de enfermagem; Equipe de assistência ao paciente.

\section{COMMUNITY HEALTH AGENT: FAMILY HEALTH STRATEGY PERCEPTIONS}

ABSTRACT: This study's objective was to understand the meaning of being a Community Health Agent (ACS) in a Family Health Program (PSF). Descriptive, qualitative, with phenomenological inspiration research that sought the essence of the ACS' speech, and all them work in the city of Sete Lagoas-MG. The interviews were recorded with 7 ACS, guided by the question "what is your perception about family health strategy, as a Community Health Agent?” The comprehensive analysis of speech allowed the construction of five categories: ACS, link between the team and the community; professional evaluation; the ACS role in the team and their contribution to the change of basic care model; training; unhealthy work conditions. It showed that the Agents of Family Health are aware and conscious of their role within the team, feel unprepared to exercise all their tasks, devalued in relation to community and other team members. Also, they perceive the occupational hazards of the profession and lack of actions to minimize them, beyond the low payment.

KEYWORDS: Family health program; Nursing care; Patient care team.

\section{AGENTE COMUNITARIO DE SALUD: PERCEPCIONES EN LA ESTRATEGIADE SALUD DE LAFAMILIA}

RESUMEN: El estudio tuvo como objetivo comprender el significado de ser un agente comunitario de salud - ACS en un Programa de Salud de la Familia (PSF). Investigación descriptiva, cualitativa, con inspiración fenomenológica que buscó la esencia del discurso del ACS en la ciudad de Sete Lagoas-MG. Las entrevistas fueron grabadas con siete ACS a partir de cuestión norteadora: ¿cuál es su percepción como un Agente Comunitario de Salud en la Estrategia de Salud de la familia? El análisis comprensivo de los discursos posibilitó la construcción de cinco categorías: ACS, enlace entre el equipo multiprofesional y la comunidad; valorización profesional; el papel del ACS en el equipo multiprofesional y su contribución para la mudanza del modelo de atención básica; formación profesional; condiciones de trabajo insalubres. Se demostró que el Agente de Salud de la Familia tiene conocimiento y conciencia de su papel dentro del equipo multiprofesional, se sienten despreparados para ejercer todas sus atribuciones, desvalorizados en relación a la comunidad y a otros miembros del equipo. Percibieron los riesgos ocupacionales de la profesión y la falta de acciones para minimización de estos, además de baja remuneración. PALABRAS CLAVE: Programa de salud de la familia; Cuidados de enfermería; Equipo de asistencia al paciente.

${ }^{1}$ Enfermeiro do SAMU de Sete Lagoas-MG. Mestre em Bioética pelo Centro Universitário São Camilo-SP. Coordenador dos Cursos de Especialização em Programa Saúde da Família, Enfermagem em Urgência, Emergência e Trauma, Enfermagem em UTI adulto e neonatal do Instituto de Educação Continuada-IEC da Pontifícia Universidade Católica de Minas Gerais-PUCMG.

${ }^{2}$ Enfermeira pela Universidade José do Rosário Vellano-UNIFENAS-BH.

${ }^{3}$ Enfermeira pela Universidade José do Rosário Vellano-UNIFENAS-BH.

${ }^{4}$ Enfermeiro pela Universidade José do Rosário Vellano-UNIFENAS-BH.

${ }^{5}$ Enfermeiro pela Universidade José do Rosário Vellano-UNIFENAS-BH.

${ }^{6}$ Graduanda de Enfermagem pela Faculdade Ciências da Vida-FCV-MG.

Autor correspondente:

Júlio César Batista Santana

Pontifícia Universidade Católica de Minas Gerais

R. Alberto da Veiga Guinard, 153 - 35700-971 - Sete Lagoas-MG, Brasil

Recebido: 23/01/09

E-mail: julio.santana@terra.com.br

Aprovado: 10/09/09 


\section{INTRODUÇÃO}

A Estratégia Saúde da família-ESF, é um modelo de reorientação do modelo assistencial, uma denominação reformulada do que antes conceituava o Programa Saúde da Família-PSF, que visa contemplar todas as fases de vida do ser humano e têm um caráter de integralidade. Isto significa que o atendimento prestado pelos profissionais da ESF deve abranger não só o aspecto biológico, mas também o psicossocial do ser humano, realizando assistência centrada na pessoa ao invés da sua doença ${ }^{(1)}$.

O ano de 1994 foi eleito, pela Organização das Nações Unidas-ONU, o Ano internacional da Família. Neste mesmo período, o Ministério da Saúde-MS anunciou a criação do Programa Saúde da FamíliaPSF, atualmente Estratégia Saúde da Família-ESF, com vistas a seguir as diretrizes previstas no Sistema Único de Saúde-SUS.

A ESF é um modelo de atenção primária, operacionalizado mediante estratégias/ações preventivas, promocionais, de recuperação, reabilitação e cuidados paliativos das equipes de saúde da família, comprometidas com a integralidade da assistência à saúde, focado na unidade familiar e consistente com o contexto socioeconômico, cultural e epidemiológico da comunidade em que está inserido ${ }^{(2)}$.

Nesta estratégia, o trabalho das equipes é um dos elementos-chave para o alcance dos objetivos desse modelo de assistência, o qual visa integrar e organizar as atividades em um território definido, sendo o seu acompanhamento de responsabilidade das equipes. Cada território é geograficamente delimitado e composto por cerca de 1 mil famílias e 3 mil a 4 mil e 500 pessoas ${ }^{(3)}$.

As equipes de Saúde da Família são minimamente compostas por um médico generalista, um enfermeiro, um auxiliar de enfermagem e quatro a seis Agentes Comunitários de Saúde-ACS. O total de Equipes de Saúde da Família em julho de 2008 era 28.879, compostas de 15.338 equipes de ACS, que acompanham um total de 9.028.124 famílias em todo Brasil $^{(3)}$. O ACS tornou-se categoria profissional em 10 de julho de 2002, após disputa de interesses sobre mercado de trabalho e controle do exercício profissional $^{(4)}$.

Perante essa equipe multiprofissional, é de responsabilidade do ACS ações de prevenção e promoção, promover a educação à saúde e mobilização comunitária para melhorias do meio ambiente, com ações de saneamento básico e incentivo à participação da comunidade, informar e direcionar a comunidade acerca dos serviços de saúde existente e como utilizálos realizando, assim, ações de promoção social e desenvolvimento da cidadania, mapear sua área de abrangência (micro área) e cadastrar e realizar acompanhamento constante através de visitas domiciliares individuais ou coletivas ${ }^{(5)}$.

O trabalho do ACS ganhou forças a partir da criação, em 1991, do Programa de Agentes Comunitários de Saúde-PACS, entendido como um programa de transição para implantação da ESF, composta por um enfermeiro para supervisão de trinta ${ }^{(6)}$.

O ACS possui um papel importante no processo de trabalho da ESF, pois atua como elo entre a comunidade e os demais membros da equipe de Saúde da Família, principalmente pelo vínculo que deve estabelecer com a família, o qual pode proporcionar confiança, solidariedade e respeito, aspectos fundamentais na promoção da saúde.

As funções do ACS transcendem o campo da saúde, pois

na medida em que, para serem realizadas, requerem atenção a múltiplos aspectos das condições de vida da população, situados no âmbito daquilo que se convenciona chamar de ação intersetorial ${ }^{(7: 6-7)}$.

Neste sentido o ACS é considerado o elo entre a equipe de saúde e comunidade, na medida em que se estabelece um vínculo com a mesma, o que permite a associação entre as informações técnico-científicas e o saber popular, facilitando o acesso dos usuários aos serviços de saúde.

Ao considerar o quantitativo de ACS, suas atribuições na equipe, bem como sua importância como elo entre comunidade e equipe multiprofissional, justifica-se uma pesquisa que tem por objetivo compreender o significado de ser um ACS no cotidiano laboral da ESF. Estudos como este poderão contribuir na construção de conteúdos para a formação e capacitação de ACS, avaliação de alguns problemas na área da saúde e apoio na tomada de decisões com a participação de toda e equipe multiprofissional.

\section{METODOLOGIA}

Trata-se de estudo qualitativo, com enfoque fenomenológico, buscando a essência do discurso do Agente Comunitário de Saúde em um Programa Saúde da Família.

Na filosofia fenomenológica há uma busca de recolocar o homem em seu devido lugar, em sua 
experiência vivida, antes de qualquer reflexão e objetiva descrever, explicar e compreender a essência e o significado dessa experiência ${ }^{(8)}$.

Desta forma, possibilita a aproximação da pessoa, do seu mundo vivido, percebendo-a com seus sentimentos, frustrações e inferências ao compreender os significados por ela atribuídos ao fenômeno em estudo. Para compreender o homem, é preciso entender que o ser-aí ou DASEIN é o ser-no-mundo, é o ser-no-mundo-com-os-outros, e isso inclui a característica fundamental de como o ser se relaciona, atua, sente-se, pensa, vive com meus semelhantes. Portanto, essa experiência não é isolada, dá-se numa relação interpessoal e subjetiva e o fenômeno não se desvela totalmente porque sempre haverá um sujeito para o qual ele se mostra em diferentes perfis ${ }^{(9)}$.

Na abordagem qualitativa não é o número de sujeitos que determina o critério de validade, mas a revelação dos fenômenos. Tal revelação se apresentou a partir da saturação das falas dos sujeitos que se mostraram suficientes para desvelar os fenômenos ${ }^{(10)}$. A pesquisa qualitativa incorpora a questão do significado e da intencionalidade como inerentes aos atos, às relações, às estruturas sociais, não sendo quantificado ${ }^{(11)}$. O pesquisador, ao buscar a essência nos depoimentos do sujeito, do seu falar espontâneo, não deve ter julgamentos prévios e sempre ter em mente uma questão norteadora que possibilita o fluir de um livre relato, permitindo mostrar o fenômeno realmente como ele é, no seu próprio discurso ${ }^{(10)}$.

Esta pesquisa foi aprovada pelo Comitê de Ética da Universidade Jose do Rosário Vellano-UNIFENAS, sob o parecer de n. ${ }^{\circ} 135 / 2008$, respaldada na Resolução n. ${ }^{\circ} 196 / 96$.

Assim, foram entrevistados sete ACS do município de Sete Lagoas-MG. Como critério para participação foi ser ACS do município de Sete Lagoas, ambos os sexos e qualquer idade que aceitasse participar voluntariamente. A fim de manter o anonimato foram utilizados os seguintes pseudônimos para identificar as falas dos sujeitos de pesquisa: ACS1, ACS2...

As entrevistas foram realizadas nas unidades de ESF, escolhidas aleatoriamente, no mês de setembro de 2008. Uma ficha de identificação e uma entrevista gravada contemplando a questão norteadora: Qual a sua percepção como Agente Comunitário de Saúde no cotidiano de trabalho desenvolvido no Programa Saúde da Família?

Após as gravações das entrevistas, estas foram transcritas na íntegra. Optamos pela análise temática, que é uma técnica de análise de conteúdo. Os discursos foram analisados, pontuando as categorias, contextualizando-os com o referencial teórico e trabalhando com um universo de significados dos fenômenos. Operacionalmente foram seguidas três etapas: pré-análise, exploração do material e o tratamento dos resultados e interpretações ${ }^{(12)}$.

\section{RESULTADOS E DISCUSSÃO}

\section{Caracterização dos sujeitos}

Dos participantes do estudo, 85\% são do sexo feminino e $70 \%$ estão na faixa etária entre 20 a 30 anos; $15 \%$ estão entre 31 a 40 anos e $15 \%$ entre 50 60 anos; 30\% possuem um tempo médio de 1 a 3 anos de serviço, $45 \%$ de 4 a 6 anos e $30 \%$ de 7 a 9 anos.

Historicamente há relatos de mulheres como cuidadoras desde o Antigo Testamento Bíblico. Na Idade Média, a imagem da mulher como cuidadora estava relacionada à religiosidade, o que pode ter suscitado maior adesão ao cuidado pela mulheres ${ }^{(13)}$.

Essa sobrecarga do trabalho reflete diretamente na construção da identidade social e individual e o trabalho, quando não desprovido do seu valor simbólico, contribui para a construção de identidade e da realização no campo social e pessoal. Portanto, o que a pessoa faz e o tempo que ela exerce determinada profissão reflete a sua percepção e interação com o mundo ${ }^{(14)}$.

O tempo que os sujeitos trabalham como ACS reflete a interação que eles estabelecem com as atividades e a visão que adquirem através do trabalho que desenvolvem. Assim, surgiram as categorias: ACS: elo entre a equipe multiprofissional e a comunidade; Trabalho em equipe: aspecto fundamental no Programa Saúde da Família; Desvalorização do profissional: aspecto que influencia na desmotivação pelo serviço; Papel do ACS na equipe multiprofissional e sua contribuição para a mudança do modelo de atenção básica; Formação profissional e Condições de trabalho insalubres.

\section{ACS: elo entre a equipe multiprofissional e a comunidade}

Nas falas abaixo é perceptível que o ACS tem consciência do vínculo estabelecido entre a comunidade e a assistência e que é através dele que a comunidade tem acesso a informações e aos 
profissionais de saúde.

[...] o trabalho do ACS é muito importante [...] é uma ponte de ligação da pessoa na casa dela com o médico e com o programa em si [...] quem convive com aquela pessoa é o ACS (ACS7).

[...] nós somos a porta de entrada para a família, graças ao meu trabalho, as pessoas do meu bairro serão mais bem atendidas, pois nós estamos ligados diretamente às famílias (ACS4).

[...] sem o ACS o PSF não teria condição, pois é a gente que vai às casas das pessoas, que conhece os problemas e quem traz esses problemas até a equipe (ACS5).

O ACS é um elo entre os objetivos das políticas sociais do Estado e os objetivos próprios da comunidade; entre as necessidades de saúde e saber popular da comunidade e o saber científico da equipe de saúde, desempenhando o papel de mediador social ${ }^{(7)}$.

Percebe-se nas falas dos sujeitos a importância do contato direto dos ACS com a comunidade, pois através das visitas domiciliares é que serão levantados os problemas e repassados à equipe, em busca de soluções, propiciando uma assistência integralizada.

Trabalho em equipe: aspecto fundamental no Programa Saúde da Família

As falas do ACS demonstram que o trabalho em equipe traz benefícios à comunidade na medida em que entrelaça saberes diversos de cada profissional envolvido, o que contribui para uma visão do ser humano de forma multidisciplinar.

[...] o trabalho de um é o trabalho de todos, portanto a dificuldade de um também se transforma na dificuldade de todos (ACS.7).

[...] todo mundo da equipe está ligado, porque se a gente não trabalhar com o médico, enfermeiro, psicólogo, todo mundo passando informação um para outro não tem como existir trabalho em equipe (ACS.3).

[...] o médico pode assentar com o ACS e o ACS sabe explicar o que acontece dentro da casa da pessoa [...] sabe que ele tem problemas e conhece esses problemas de perto [...] tem coisas que ele vai contar prá gente que ele não conta para o médico (ACS.7).

A liberdade de expressão é fundamental no processo do trabalho em equipe, uma vez que para assistir à saúde da família a opinião de cada profissional contribui para a qualidade da assistência. Essa situação está evidenciada nas falas:

[...] como ACS, sinto que a equipe respeita o meu trabalho e dão valor às minhas opiniões e aos problemas que levo (ACS 7).

[...] sempre sou atendido pelo médico e enfermeira, quando levo um problema, mesmo sendo um ACS, talvez sem um curso superior, mas com o conhecimento do dia a dia [...] eles me recebem, me dão atenção (ACS 3).

[...] a equipe confia na gente [...] valoriza o nosso saber adquirido nas experiências de trabalho que está diretamente ligado com a comunidade [...] tenho liberdade de expressar (ACS 7).

A ESF é composta por uma equipe de trabalhadores de formação superior quanto média, o que impõe desafios à Estratégia, principalmente referentes à questão de como orientar a participação de todos de forma harmônica e complementar ${ }^{(15)}$. A participação dos profissionais nas discussões da ESF é fundamental na construção de um processo de trabalho guiado por diversos olhares.

\section{Desvalorização do profissional: aspecto que influencia na desmotivação pelo serviço}

Percebe-se nas falas do ACS sentimento de desvalorização pela população. No entender deles, é pela falta de conhecimento da comunidade sobre a própria estrutura do PSF. Alegam que os usuários não compreendem que não é "culpa" do ACS os problemas do dia-a-dia: como falta de profissionais, estrutura precária dos serviços de saúde, dificuldade na marcação de exames.

[...] a gente tem um papel importante, pode ser que muitas vezes não é valorizada, a pessoa não compreende [...] porque muitas vezes a pessoa é de um jeito com o médico e com você ela trata de 
outro jeito [...] a gente comenta que aqui no PSF que valor dentro do PSF é de enfermeiro prá cima [...] o ACS não serve prá nada como diz o povo [...] muita gente não vê essa importância do ACS com a família (ACS.7).

[...] uns aceitam muito bem, outros acham que nem deveria existir que é perda de tempo nosso trabalho (ACS.6).

[...] com cada indivíduo você age de uma forma, umas te cumprimenta, outras fecham as portas quando você passa (ACS.5).

O não-reconhecimento profissional faz com que algumas pessoas adoeçam, reclamem, se sintam desmotivadas e com diminuição do comprometimento com o trabalho. Isso pode refletir na responsabilidade do sujeito e na forma de enfrentar estes conflitos e fazer a diferença no ambiente de trabalho(14).

A desvalorização profissional por meio da baixa remuneração, da insegurança pelo tipo de contrato, dos descontos em folha de pagamento e da falta de estímulos e gratificação, também podem levar o ACS a uma desmotivação no serviço.

[...] quando eu penso em valor profissional, me vem à mente a questão salarial [...] eles tinham que olhar mais pela gente [...] são 8 horas trabalhadas por dia, e a maioria do tempo no sol (ACS.1).

[...] agente não tem segurança nenhuma, o salário é desvalorizado [...] é muito pouco pelo tanto que faz (ACS.2).

[...] a falta de valorização deixa a pessoa com a autoestima baixa e acaba que você não faz seu trabalho direito por falta de motivação, os descontos na folha de pagamento, a insegurança de ser contratado, tudo isso gera certa insatisfação (ACS.7).

[...] considerando as condições de trabalho a remuneração não é muito boa, se você quiser, por exemplo, tentar uma faculdade com o salário de ACS, você sozinha não consegue, então não tem nem como melhorar sua condição sozinha (ACS.7).

Em um estudo realizado com ACS a insegurança pelo tipo de contrato, não-valorização profissional da categoria, não-recebimento de algumas vantagens destinadas ao ACS, a precariedade dos serviços e o desconto de impostos foram apontados como causas de insatisfação do profissional ${ }^{(16)}$.

\section{Papel e contribuição do ACS na equipe multiprofissional}

Ao agente de saúde se atribui o que transcende à sua formação profissional. A complexidade do que foi colocado pelo Ministério da Saúde como papel do ACS exige uma variedade de profissionais cuja formação vai além de um simples treinamento. Fazse necessário que o ACS se comunique com os demais, que conheça suas próprias atribuições e competências e também as competências dos outros membros da equipe. Profissionais que o ACS conhece de perto e que, como relatam as falas citadas a seguir, sabem acioná-los quando se faz necessário.

[...] uma criança de 8 anos, a mãe trabalhava e deixava a criança sozinha, aí eu conversei com o conselho tutelar e o conselho tutelar foi lá e no outro dia chegou a carta respondendo a decisão do conselho e mostrando a solução para a família (ACS.6).

[...] eu tive um caso na minha área de uma família que veio morar aqui e não conseguiu vaga na escola prá filha, depois que a mãe dela me falou eu procurei a assistente social e ela conseguiu que a menina entrasse na escola [...] é muito gratificante saber que eu posso ajudar (ACS.1).

O trabalho em equipe está intimamente relacionado à ESF, mas para que isso ocorra faz-se necessário que o município viabilize essa integração, contratando uma maior variedade de profissionais para compor essa equipe de saúde, distanciando daquele modelo de atenção curativista centrado na figura do médico e no hospital, para um modelo de assistência completa, voltado para um ser humano integral, membro de uma família inserida numa sociedade.

Neste contexto percebe-se que seu trabalho fica prejudicado por não haver incentivos pelos gestores e uma visão equivocada da população, do papel do ACS, que vai muito além de marcar consultas e entrega de exames complementares.

[...] a gente trabalha com trabalho preventivo em 
relação às doenças e endemias que tem. É muito difícil entrar na casa de um paciente e não ter médico, eles não compreendem que o PSF é prevenção de doenças. Eles querem que agente chegue e já está com a consulta em mãos (ACS.2).

[...] o prefeito e a secretaria deveria elaborar melhor os cursos [...] e inserir a comunidade para ficar mais claro o que é o PSF e sua finalidade (ACS.3).

[...] tem muita gente que ainda pensa naquele sistema de posto de saúde [...] se tem um problema vai lá e resolve com o médico [...] agora não é mais assim [...] eu vou lá na casa da pessoa saber o que está acontecendo com ela, passo as informações, acompanho [...] demora prá deixar essa visão perder (ACS.5).

Nas falas dos sujeitos abaixo se percebe que alguns ACS questionam a "super-heroização" do seu papel. As atribuições do ACS e seu papel têm sido distorcidos, quando se atribui a este profissional o papel de ser a "mola propulsora da consolidação do SUS", sobrecarregando seu trabalho. Comenta também que o processo de transformação social é um processo lento e é papel de todos os cidadãos ${ }^{(17)}$.

[...] é claro que a gente faz outras coisas também [...] não é o que eu via pela televisão. [...] a percepção era mais da enfermagem do que esse acompanhamento nosso como agente, porque o que ACS faz é uma prevenção, ele informa, ensina e tal, bem diferente do que eu imaginava que fosse (ACS.2).

[...] a gente passa até do que deveria, ajudando o pessoal no que eles precisam, com um acesso mais perto e fácil de conseguir as coisas (ACS.6).

\section{Formação profissional}

É necessário instruir o ACS no sentido de incorporar à sua formação profissional o conhecimento sobre a abordagem das famílias, na interação cotidiana com a comunidade, instruindo-o a identificar certas necessidades desta ${ }^{(18)}$.

Nas falas abaixo os sujeitos relatam que não foram suficientemente preparados para exercerem tais atribuições, aprendendo na prática aquilo que deveria ter sido preparado antes de exercerem efetivamente a profissão.

[...] nós tivemos um curso de seis meses na escola de saúde onde eles ensinam para a gente muitas coisas sobre a comunidade. Esse curso era feito no centro e também na comunidade. Quando eu entrei aqui na unidade a enfermeira fez uma reciclagem com as meninas que já estavam $e$ passou tudo sobre PSF para mim, então eu pude ter um preparo sobre nossas funções com a enfermeira e sempre está tendo alguns cursos que a prefeitura passa para nós (ACS.2).

[...] eu não fiz nenhum treinamento prá entrar, fiz cursos depois que eu já estava trabalhando, entrei sem preparo nenhum (ACS.3).

[...] o ACS gosta muito de ajudar e se não tem uma clareza de doença, de muitas coisas ele vai ficar perdido [...] logo que ele entra, ele tem que saber como que ele vai trabalhar prá poder ajudar a população (ACS.6).

O processo de qualificação do ACS ainda é desestruturado, fragmentado e, na maioria das vezes, insuficiente para desenvolver as novas competências necessárias para o adequado desempenho de seu $\operatorname{papel}^{(4)}$.

As múltiplas funções desempenhadas pelo ACS demandam um conhecimento e uma visão abrangente, o que remete novamente à importância do trabalho contínuo com a equipe, tendo a oportunidade de adquirir saberes diversos. Todos os profissionais de saúde devem estar envolvidos nessa formação, pois ela irá refletir no melhor atendimento à comunidade.

\section{Condições de trabalho insalubres}

As condições de trabalho dos ACS são insalubres por apresentarem riscos à saúde como exposição ao sol, exposições a doenças as quais ele não tem um conhecimento adequado para se protegerem, exposições a pessoas de tantas personalidades diferentes e outras.

Os sujeitos explicitam que a remuneração recebida não é suficiente mediante os riscos aos quais são expostos diariamente e que não percebem uma preocupação por parte dos gestores. 
[...] aqui na nossa área tem problemas com tráfico, essas coisas, a gente não tem muita segurança [...] tem lugares que o ACS não pode ir sozinho, porque é bem perigosa, a gente tem medo de entrar [...] nessa questão de segurança, falta muito (ACS.6).

[...] tem casas que a gente sabe que a pessoa é estuprador e que já fez um tanto de coisas, eu fico com medo. [...] a gente não tem segurança nenhuma, mesmo entrando lá com uma colega, outra ACS, a gente não sabe o que pode acontecer. (ACS.4).

Os danos causados pela exposição aos raios ultravioletas são cumulativos e o risco de desenvolvimento de melanoma em uma pessoa exposta por mais ou menos três anos é três vezes maior do que uma pessoa que não atua nessas condições ${ }^{(19)}$. Ressalta-se que é responsabilidade do empregador o fornecimento de produtos para a proteção diária do trabalhador, devido a este ser sabidamente lesivo à saúde deste profissional.

Trabalhadores de quaisquer profissões se expõem aos riscos e condições desfavoráveis de trabalho por temerem pela oferta de força de trabalho igual a que exercem, sentimento de perda pelo mercado, evitando atitudes contrárias com a administração, contribuindo diretamente para que as condições desfavoráveis perpetuem ${ }^{(14)}$.

O trabalho exercido sob riscos de agressão física compromete a qualidade de vida desse trabalhador, principalmente pelo fato de o ACS fazer parte da comunidade. Isto pode, indiretamente, colocar a sua família sob condições de risco, comprometendo assim a qualidade e desenvolvimento do trabalho.

\section{CONCLUSÃO}

Os ACS vislumbram seu trabalho com satisfação em colaborar com a comunidade sendo um articulador, da equipe multiprofissional, entre esta e a comunidade.

Muitos se sentem despreparados para exercer algumas atribuições, ao relatar que sua formação profissional é mais prática do que teórica, sendo esta última fragmentada, o que desfavorece a visão do indivíduo como unidade indissociável, como ser único e holístico.

Revelam o sentimento de desvalorização pela comunidade, na qual a maioria desconhece a finalidade do PSF, se baseiam ainda no modelo de atenção passado, não havendo uma efetiva promoção pelos administradores para que realmente haja participação da comunidade no processo de saúde, sendo esta apontada pelos ACS como um dos fatores que impede a implantação real do programa.

Sentem-se desvalorizados em relação às condições salariais, tipo de contrato e falta de ações efetivas para melhoria dessa, o que resulta em desmotivação pelo trabalho.

A prática diária de trabalho expõe os ACS a riscos ocupacionais referentes a risco de agressão física, exposições excessiva ao sol e a doenças, e não são desenvolvidas ações de proteção efetiva a esse trabalhador, tais como acréscimo de insalubridade, por exemplo. A fim de tornar pública a real finalidade da ESF e qual a importância do trabalho do ACS, se faz necessária a promoção de campanhas junto à comunidade para definir as prioridades de saúde local.

A força de trabalho do ACS é imprescindível para consolidação dos princípios do SUS, pois torna a saúde mais acessiva para uma camada da população desprovida de condições de arcar financeiramente com sua própria saúde e saúde da sua família, além de levar até o domícilio das pessoas as informações necessária no que diz respeito à saúde como modelo que privilegia a prevenção.

Este estudo abre questionamentos para novas pesquisas e não há pretensão de considerar essa temática esgotada, contribuindo assim para refletir as práticas no cotidiano laboral dos profissionais inseridos na equipe e em especial do ACS.

\section{REFERENCIAS}

1. Maciel ME. A equipe de saúde da família e o portador de transtorno mental: relato de uma experiência. Cogitare Enferm. $2008 \mathrm{Jul} / \mathrm{Set} ; 13(3): 453-6$.

2. Campos GWS. Tratado de saúde coletiva. São Paulo: Hucitec; 2006.

3. Ministério da Saúde (BR). Agentes comunitários de saúde, equipe saúde da família e equipes de saúde bucal em atuação. 2005. [Acesso em 2008 Set 20]. Disponível: http//portal saúde.gov.br/saúde.

4. Bachilli RG, Scavassa AJ, Spiri WC. A identidade do agente comunitário de saúde: uma abordagem fenomenológica. Cienc Saúde Col. 2008;Jan/ Fev;13(1):51-60.

5. Ministério da Saúde (BR). Secretaria de Políticas de 
Saúde. Departamento de Atenção Básica. A implantação da Unidade de Saúde da Família: caderno de atenção básica 1. Brasília, 2000.

6. Martines WRV, Chaves EC. Vulnerabilidade e sofrimento no trabalho do agente comunitário de saúde no Programa de Saúde da Família. Rev Esc Enferm USP. 2007 Set;41(3):423-33.

7. Nogueria RP, Silva FB, Ramos ZVO. A vinculação institucional de um trabalhador sui generis: o agente comunitário de saúde. Rio de Janeiro: IPEA; 2000.

8. Capalbo C. Alternativas metodológicas de pesquisa. In: Seminário Nacional de Pesquisa em Enfermagem, cap. 3, 1984, Florianópolis. Anais. Florianópolis: Universidade Federal de Santa Catarina, 1984.

9. Heidegger M. Ser e tempo. 9a ed. Petrópolis: Vozes; 2000.

10. Santana JCB. Avanços tecnológicos e os limites dentro de uma Unidade de Terapia Intensiva no processo ético do cuidar: significado para os acadêmicos de enfermagem. Bioethikos. 2008 Abr;2(1):73-80.

11. Minayo MCS. O desafio do conhecimento: pesquisa qualitativa em saúde. 8a ed. São Paulo: Hucitec; 2004.

12. Bardin L. Análise de conteúdo. Lisboa: Edições 70; 2000.

13. Nauderer TM, Lima MADS. Imagem da enfermeira: revisão da literatura. Rev Bras Enferm. 2005 Jan/ Fev;58(1):74-7.

14. Nakagawa PY. Reflexão: o sofrimento do trabalhador. 2007. [Acesso em 2008 Out 18 ]. Disponível: www. palavraescuta.com.br.

15. Cecílio LCO. Uma sistematização e discussão de tecnologia leve de planejamento estratégico aplicada ao setor governamental In: Merhy EE, Onoko R, organizadores. Agir em saúde: um desafio para o público. São Paulo; 1997.

16. Vilar RLA, Castro JL, Fernandes VP. Precarização do trabalho do agente comunitário de saúde: um desafio para a gestão do SUS. In: Barros AFR, Santana JP, Santos Neto PM, organizadores. Observatório de recursos humanos em saúde no Brasil. Brasília: Ministério da Saúde; 2004. v. 2, p. 105-120.

17. Bornstein VJ, Stotz EN. Concepções que integram a formação e o processo de trabalho dos agentes comunitários de saúde: uma revisão da literatura. Cienc
Saúde Col. 2008 Jan/Fev;13(1):259-68.

18. Nunes MO, Trad LB, Almeida BA, Homem CR, Melo MCIC. O agente comunitário de saúde: construção da identidade desse personagem híbrido e polifônico. Cad Saúde Publ. 2002 Nov/Dez.;18(6):1639-46.

19. Mattos RP. O risco da exposição ao sol na construção civil. [Acesso em 2008 Out 12]. Disponível: http://www. ricardomattos.com/uvray.htm.

Cogitare Enferm 2009 Out/Dez; 14(4):645-52 